\title{
'Minor' Illness Symptoms
}

\section{Citation}

Anthony L. Komaroff. 1990. 'Minor' Illness Symptoms. JAMA Internal Medicine 50, no.

8:1586-1587.

\section{Published Version}

10.1001/archinte.1990.00040031586003

\section{Permanent link}

http://nrs.harvard.edu/urn-3:HUL.InstRepos:42656565

\section{Terms of Use}

This article was downloaded from Harvard University's DASH repository, and is made available under the terms and conditions applicable to Other Posted Material, as set forth at http:// nrs.harvard.edu/urn-3:HUL.InstRepos:dash.current.terms-of-use\#LAA

\section{Share Your Story}

The Harvard community has made this article openly available.

Please share how this access benefits you. Submit a story.

Accessibility 


\section{'Minor' Illness Symptoms}

\section{The Magnitude of Their Burden and of Our Ignorance}

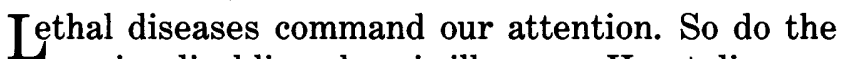
major disabling chronic illnesses. Heart disease, cancer, stroke, the acquired immunodeficiency syndrome, arthritis, diabetes, schizophrenia - these and other "major" diseases are the object of our fears. A large fraction of our annual expenditures for patient care and research are used to deal with these illnesses.

Any clinician knows, however, that many of the problems that patients bring to the doctor's office are "minor" illnesses. Data from the National Ambulatory Medical Care Survey, conducted by the National Center for Health Statistics, Bethesda, Md, make the following point: in one year, there were 62 million office visits for acute respiratory tract infection symptoms, back pain, and headache, in contrast with 17 million visits for chronic ischemic heart disease and diabetes. ${ }^{1}$

\section{See also $p 1685$.}

Moreover, the frequency of minor illnesses dwarfs the frequency of major illnesses when one considers the many instances of minor illness that are never brought to the doctor's attention at all. In a careful 10-year prospective study of 443 individuals in 86 families, followed up for a total of 970036 persondays, Dingle ${ }^{2}$ and his staff kept a careful record of conditions that caused significant enough impairment to be described as illnesses by these subjects. There were 9.4 illnesses per person-year, of which $5.6(60 \%)$ were for common respiratory diseases. By contrast, no individual experienced a myocardial infarction or angina pectoris, and only one developed a malignancy. $^{2}$

Even more common than minor illnesses are symptoms that could be defined as an illness. When is a symptom an illness? Even apparently similar Western societies may differ in the threshold at which a symptom becomes an illness. ${ }^{3}$ Within our society, the answer appears to be quite variable from one person to the next. In a survey of over one million individuals conducted by the American Cancer Society, Atlanta,
$\mathrm{Ga}, 40 \%$ to $55 \%$ of individuals stated that they were experiencing headaches, $33 \%$ to $46 \%$ fatigue, and $15 \%$ sore throat at the time surveyed. ${ }^{4}$ Typically, these symptoms were described as being only of "slight" severity. Contrasting these data with the study of Dingle, ${ }^{2}$ it appears that most individuals do not regard most symptoms as being illnesses, most of the time.

The minor illnesses can be enormously costly for society. The huge market in over-the-counter drugs is largely generated by the symptoms of minor illness. Common acute respiratory infections, for example, account for more than 100 million days of lost productivity each year in the United States, a greater loss of productivity than is caused by all strikes, work stoppages, and lockouts combined. ${ }^{5} \mathrm{We}$ estimate that nearly $\$ 2$ billion per year is spent in the diagnosis and treatment of common acute respiratory infections. Estimates are that low back pain costs American society at least $\$ 16$ billion each year. ${ }^{6}$

Elsewhere in this issue of ARCHIVES, Kroenke and colleagues $^{7}$ report a study that makes another important point: many patients with symptoms of minor illness obtain little benefit from their encounter with the health care system. Five hundred medical outpatients were surveyed prospectively, regardless of their reason for seeking medical care. Among these patients, 410 indicated that they currently were suffering from symptoms that they regarded to be "major problems." The most prevalent symptoms were fatigue (33\% of patients interviewed) and back pain $(32 \%)$.

Another recently reported study by Kroenke and Mangelsdorff $f^{8}$ makes another important point: the clinician is often uncertain as to the basis for many common acute symptoms. Kroenke and Mangelsdorff surveyed the care received by 1000 individuals and examined those instances in which patients had presented with any of 14 different common acute symptoms, such as fatigue, headache, back pain, and cough. They found that an organic basis was established in only 16\% of cases; a psychologic basis was 
assumed in $10 \%$ of cases; and, in $74 \%$ of cases, the origin of the symptoms was unknown. ${ }^{8}$

Some of these $74 \%$ of cases probably reflect unrecognized psychiatric disorders. It is widely assumed that the basis for many common symptoms is psychological, that the patient has expressed a psychiatric disorder through "nonpsychiatric" symptoms. ${ }^{9}$ While this is nearly impossible to prove absolutely, it is widely believed. Indeed, several symptoms that could reflect an underlying "organic" disorder - chest pain, dyspnea, palpitations, abdominal pain, nausea, diarrhea, weight change, energy loss, sweating, dizziness, numbness, back pain, hypermenorrhea, and others - serve as a basis for diagnosing psychological disorders such as depression, anxiety, panic disorder, and somatization disorder, according to the Diagnostic and Statistical Manual of Mental Disorders, revised, (American Psychiatric Association, Washington, DC). Indeed, a number of studies indicate that primary care clinicians may fail to recognize psychiatric disorders when patients focus on the somatic manifestations of a psychiatric illness. Two recent studies indicate that internists fail to recognize depression nearly half of the time, ${ }^{10,11}$ and that psychiatric disorders are prevalent in general medical practice. ${ }^{12}$

At the same time, the clinician may also be prone to overdiagnose psychiatric illness in a patient with vague symptoms of minor illness. Before a pathophysiologic basis was established for systemic lupus erythematosus, Lyme disease, or multiple sclerosis, for example, patients with these illnesses who presented with fatigue, headaches, myalgias, arthralgias, blurred vision, numbness, tingling, and related symptoms were frequently given psychiatric diagnoses. Indeed, in our experience, the same error is

still made today in some patients with these illnesses. Interestingly, a recent report finds that psychiatrists often fail to recognize organic illness that is causing or exacerbating a psychiatric symptom. ${ }^{13}$ It is easy, too easy, to diagnose a psychiatric disorder in a patient with vague symptoms when one has been unable to diagnose an organic illness.

There is no happy answer to this dilemma. Substantial sums can be spent and, perhaps, wasted searching for an organic diagnosis. For example, one study found that $\$ 8000$ had been spent to identify one organically based case of headache and $\$ 7000$ to identify one organically based case of back pain. ${ }^{8}$

Whatever the basis of many common symptoms, remarkable physical and psychosocial impairment can be associated with minor illnesses. In a landmark study of fatigue in a general medical practice, Kroenke et al $^{14}$ demonstrated that the degree of impairment in functioning, as determined by formal instruments, was not different for patients with fatigue from that of patients with major medical illnesses, such as survivors of myocardial infarction. ${ }^{14}$ Deyo and Diehl ${ }^{15}$ demonstrated a similar substantial degree of impairment among patients with back pain.

In summary, the minor illnesses are enormously prevalent and produce collectively a large amount of lost productivity and medical expense. They also are poorly understood and, as a consequence, patients frequently do not get relief from their encounters with the health care system. We need to learn a great deal more about the minor illnesses of mankind.

ANTHONy L. KomarofF, MD
Division of General Medicine
Brigham and Women's Hospital
Harvard Medical School
Boston, MA 02115

\section{References}

1. National Center for Health Statistics, Lawrence L, McLemore T. 1981 summary: National ambulatory medical care survey. In: Advance Data from Vital and Health Statistics, No. 88. Hyattsville, Md, US Public Health Service, 1983. US Dept of Health and Human Services publication PHS 83-1250.

2. Dingle JH. The ills of man. Sci Am. September 1973:76-84.

3. Andersen R, Anderson OW, Smedby B. Perception of and response to symptoms of illness in Sweden and the United States. Med Care. 1968;6:18-30.

4. Hammond EC. Some preliminary findings on physical complaints from a prospective study of 1064004 men and women. $A m$ $J$ Public Health. 1964;54:11-23.

5. Komaroff AL, Aronson MD, Pass TM, et al. Serologic evidence of chlamydial and mycoplasmal pharyngitis in adults. Science. 1983;222:927-929.

6. Frymoyer JW. Back pain and sciatica. N Engl J Med. 1988; 318:291-298.

7. Kroenke K, Arrington ME, Mangelsdorff AD. The prevalence of symptoms in medical outpatients and the adequacy of therapy. Arch Intern Med. 1990;150:1685-1689.

8. Kroenke $\mathrm{K}$, Mangelsdorff AD. Common symptoms in ambulatory care: incidence, evaluation, therapy, and outcome. $A m J$
Med. 1989;86:262-266.

9. Katon W, Kleinman A, Rosen G. Depression and somatization: a review: part 1. Am J Med. 1982;72:127-135.

10. Gerber PD, Barrett J, Barrett J, Manheimer E, Whiting R, Smith R. Recognition of depression by internists in primary care: a comparison of internist and 'gold standard' psychiatric assessments. J Gen Intern Med. 1989;4:7-13.

11. Wells KB, Hays RD, Burnam MA, Rogers W, Greenfield S, Ware JE. Detection of depressive disorder for patients receiving prepaid or fee-for-service care: results from the Medical Outcomes Study. JAMA. 1989;262:3298-3302.

12. Barrett JE, Barrett JA, Oxman TE, Gerber PD. The prevalence of psychiatric disorders in a primary care practice. Arch Gen Psychiatry. 1988;45:1100-1106.

13. Hall RCW, Gardner ER, Popkin MK, Lecann AF, Stickney SK. Unrecognized physical illness prompting psychiatric admission: a prospective study. Am J Psychiatry. 1981;138:629-635.

14. Kroenke K, Wood DR, Mangelsdorff AD, Meier NJ, Powell JB. Chronic fatigue in primary care: prevalence, patient characteristics, and outcome. JAMA. 1988;260:929-934.

15. Deyo RA, Diehl AK. Measuring physical and psychosocial function in patients with low back pain. Spine. 1983;8:635-652. 